\title{
Intracerebral abscess: A complication of severe cystic fibrosis lung disease
}

\author{
Mark E Fenton MSc MD FRCPC, Donald W Cockcroft MD FRCPC, John A Gjevre MD FRCPC
}

\begin{abstract}
ME Fenton, DW Cockcroft, JA Gjevre. Intracerebral abscess: A complication of severe cystic fibrosis lung disease. Can Respir J 2008;15(1):45-47.

Intracerebral abscess is an uncommon complication of severe cystic fibrosis lung disease. The present report describes a case of fatal multiple intracerebral abscesses in a patient with a severely bronchiectatic, nonfunctioning right lung and chronic low-grade infection. The patient was previously turned down for pneumonectomy. Intracerebral abscess in cystic fibrosis and the potential role of pneumonectomy in the present patient are discussed.
\end{abstract}

Key Words: Cystic fibrosis; Intracerebral abscess; Pneumonectomy

Brain abscess as a complication of cystic fibrosis (CF) is Breported infrequently in the literature $(1-4)$. We present a case of multiple intracerebral abscesses in a patient with unilateral, severe CF-related lung disease.

\section{CASE PRESENTATION}

An 18-year-old male Hutterite, diagnosed with CF (genotype unknown) at three months of age, presented with bifrontal and occipital headache, neck stiffness and vomiting for $72 \mathrm{~h}$. No recent dental work or surgical interventions were performed. He did not have an implanted intravenous access device. He had regular contact with animals because he lived on a farming colony. His right lung was severely damaged, with absence of both ventilation and perfusion demonstrated on ventilationperfusion scanning. Severe unilateral cystic bronchiectasis was demonstrated on chest radiography (Figure 1) and plain computed tomography (CT) imaging (Figure 2). His condition developed postoperatively following a nasal polypectomy at 11 years of age. Subsequently, he had difficulty maintaining his body weight, had chronic high-volume purulent sputum production, and had chronic low-grade fever with occasional hospitalization. He received chronic chest physiotherapy and daily treatment with nebulized deoxyribonuclease. The lungs were colonized with Klebsiella pneumoniae (resistant to ampicillin and trimethoprim-sulfamethoxazole) and fully sensitive Pseudomonas aeruginosa (sputum culture), and he was treated with inhaled tobramycin $80 \mathrm{mg}$ twice daily (continuously) and ciprofloxacin $500 \mathrm{mg}$ twice daily (two weeks on and two weeks off). At several points over the course of follow-up, the notion of a right pneumonectomy was raised, but it was rejected by two thoracic surgeons because of concerns about perioperative

\section{L'abcès intracérébral : Une complication de la maladie pulmonaire grave associée à la fibrose kystique}

\begin{abstract}
L'abcès intracérébral est une complication peu courante de la maladie pulmonaire associée à la fibrose kystique. Le présent cas décrit un cas de multiples abcès intracérébraux qui se sont révélés fatals chez un patient ayant un poumon droit gravement bronchiectasique et non fonctionnel et une infection bénigne chronique. Ce patient n'avait pas été admissible à une pneumonectomie. On traite de l'abcès intracérébral en cas de fibrose kystique et du rôle potentiel de la pneumonectomie chez ce patient.
\end{abstract}

complications; specifically, a 23\% incidence of bronchopleural fistula in one report (5). His forced expiratory volume in $1 \mathrm{~s}$, three months before admission, was $41 \%$ of predicted $(1.7 \mathrm{~L})$.

On examination, he was afebrile with stable vital signs. There were no papilledema or focal neurological findings. However, there was significant meningismus. There was tracheal deviation to the right, and bronchial breathing and diminished breath sounds in the right hemithorax. Digital clubbing was prominent.

Investigations revealed a leukocytosis of $22 \times 10^{9} / \mathrm{L}$ with a left shift, and a cerebrospinal fluid white blood cell count of $24.84 \times 10^{9} / \mathrm{L}$ (90\% neutrophils). A CT scan of the head demonstrated five ring-enhancing lesions - two in the posterior fossa and three in the supratentorial area (Figure 3). Chronic inflammatory changes without fluid levels were identified in the sinuses. He was admitted to the hospital, and intravenous ceftazidime, metronidazole, cloxacillin and dexamethasone were commenced. Fluconazole was subsequently added. Multiple cultures of cerebrospinal fluid, blood and urine were negative. Sputum culture was initially negative but subsequently grew two Pseudomonas strains (one mucoid), with which he was known to be colonized, and Aspergillus species (not Aspergillus fumigatus). A transthoracic echocardiogram did not demonstrate any valvular vegetations.

The patient's stay in the hospital was complicated by a fluctuating course followed by a progressive decline in neurological status, requiring placement of intraventricular drains, a ventriculoperitoneal shunt, administration of intrathecal vancomycin and intubation for respiratory failure. Despite aggressive treatment (including multiple ventricular drains and intrathecal vancomycin), his neurological status declined

Division of Respiratory, Critical Care and Sleep Medicine, Department of Medicine, University of Saskatchewan, Royal University Hospital, Saskatoon, Saskatchewan

Correspondence: Dr John A Gjeure, Division of Respiratory, Critical Care and Sleep Medicine, 5th Floor, Ellis Hall, Royal University Hospital, 103 Hospital Drive, Saskatoon, Saskatchewan S7N OW8. Telephone 306-966-1808, fax 306-966-8694, e-mail john.gjevre@usask.ca 


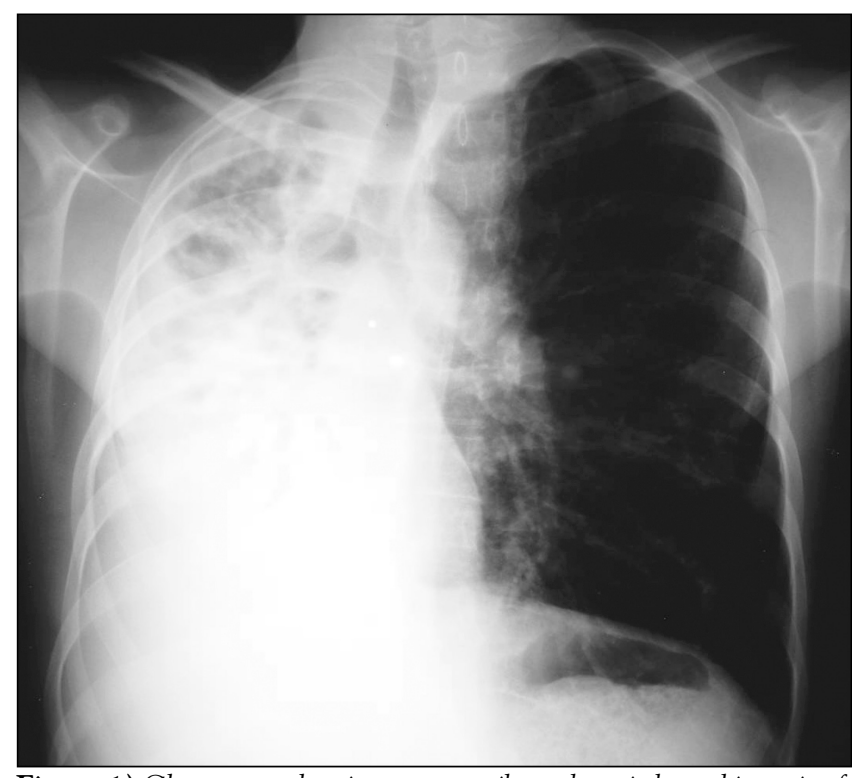

Figure 1) Chest $x$-ray showing severe unilateral cystic bronchiectasis of the right lung

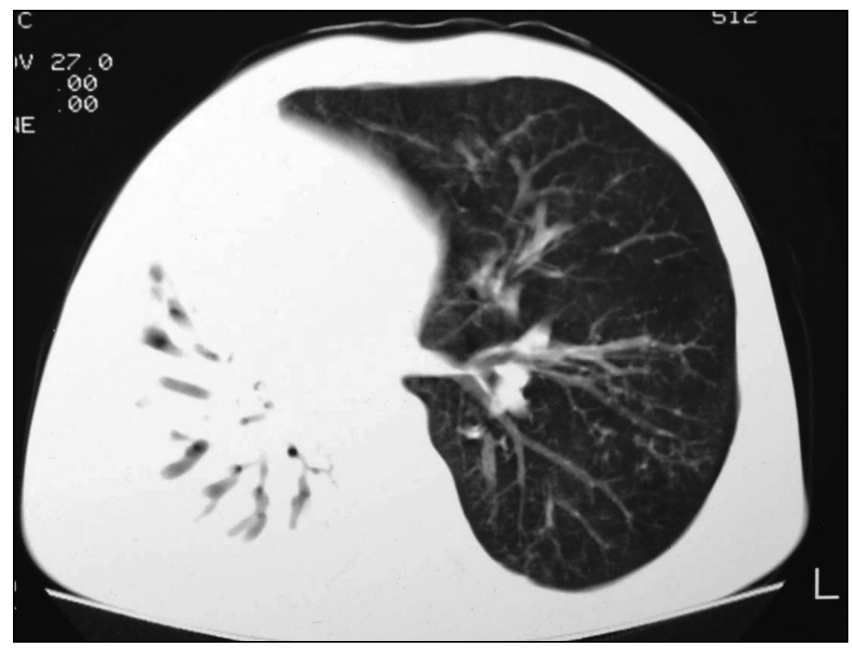

Figure 2) Computed tomography of the chest, showing severe unilateral cystic bronchiectasis of the right lung

and he developed respiratory failure. In the end, his family decided to withdraw active management and pursue compassionate terminal care. He died after 34 days in the hospital. A histological examination of cerebral tissue was not performed because an autopsy was declined by the family.

\section{DISCUSSION}

Brain abscess has long been recognized as a rare complication of CF, with only 12 cases previously reported in the literature $(1-3,6-11)$. It is a complication almost never seen in children with CF, with only one previously reported case (11). Cooper et al (6) postulated that its predilection for young adults over children may reflect an increased susceptibility to disseminated infection with advancing disease. However, systemic pseudomonal infection is exceedingly rare in CF patients, suggesting a robust immune system. Previous reports have suggested that many cases may be due to sinusitus and/or immunosuppression. Abscess formation from sinusitis is usually ipsilateral and frontal in location, and contiguous with the affected sinus

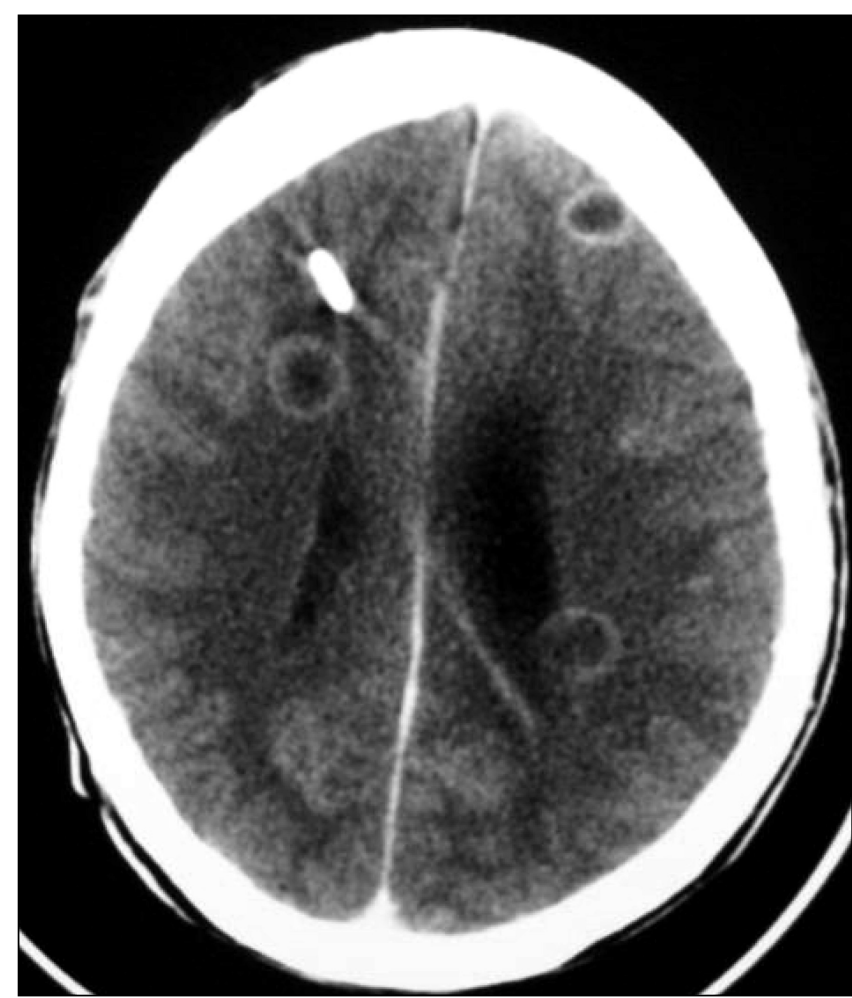

Figure 3) Computed tomography of the head demonstrating ringenhancing lesions. There is also a ventricular drain in the right frontal area

(12) - a scenario not demonstrated in our case. Others (7) have suggested a hematogenous spread of infection, most likely from an extrapulmonary source. Collis (4) postulated that intracerebral abscess associated with suppurative lung infection was due to embolic spread via retrograde flow through the vertebral veins. Wiersbitzky et al (8) also suggested that a possible mechanism for hematogenous spread from infected lung tissue to brain is via local erosion of blood vessels in chronically inflamed bronchi, leading to occult bacteremia. We hypothesize that the development of intracerebral abscess may be an effect of time and chance. There may be repeated embolic exposures throughout the life of a chronically infected CF patient, and eventually one or more will not be removed by the immune system, establishing local infection. In the present case, the presence of multiple widely dispersed abscesses favours a hematogenous mechanism of spread, with the lung as the most likely source.

The role of pneumonectomy in CF patients is controversial. Pneumonectomy has been used to try to delay progression of the disease in the affected lung through resection of the affected segments. Some authors have advocated its use to reduce infection, improve quality of life and prolong survival in chronic infection (13). Others, however, have reserved this practice only for cases with respiratory failure as a bridge to transplant $(14,15)$. Most reported cases of pneumonectomy in CF are in patients with respiratory failure (15). Our patient, who did not have respiratory failure, raises the question of the value of pneumonectomy in patients with a chronically infected/colonized nonfunctioning lung with a 'preserved' forced expiratory volume in $1 \mathrm{~s}$. Pneumonectomy in CF patients has multiple considerations chief among them are complications (eg, bronchopleural fistula, inoculation or colonization of the resected hemithorax, and 
ventilator dependence) and potential adverse effects on lung transplantation. Current literature suggests that pneumonectomy is not a contraindication to future lung transplant (14-17). The issue of pneumonectomy was raised at several points before his final hospitalization, but he was dismissed as being too risky (ie, high incidence of bronchopleural fistula) (5). A lung transplant specialist indicated that an uncomplicated postoperative course in the present patient would not preclude a future unilateral or single lung transplant of the left lung. The literature around this issue suggests that most patients do well and have improved quality of life, and reduced numbers of infections or hospitalizations $(13,14,16,17)$.

The absence of positive cerebrospinal fluid cultures in our patient, likely the result of chronic use of antibiotics, make firm associations regarding the primary source of the infection difficult. Only eight of 12 reported cases (67\%) of CF-associated lung abscess have had positive culture results, the majority of which are pathogens associated with the oral cavity rather than

\section{REFERENCES}

1. Ayres J, Kinsella H. Multiple cerebral abscesses in an adult with cystic fibrosis. Br J Dis Chest 1982;76:99-101.

2. Duffner PK, Cohen ME. Cystic fibrosis with brain abscess. Arch Neurol 1979;36:27-8.

3. Fischer EG, Shwachman H, Wepsic JG. Brain abscess and cystic fibrosis. J Pediatr 1979;95:385-8

4. Collis JL. The aetiology of cerebral abscess as a complication of thoracic diseases. J Thorac Surg 1944;13:445.

5. Reed CE. Pneumonectomy for chronic infection: Fraught with danger? Ann Thorac Surg 1995;59:408-11.

6. Cooper DM, Russell LE, Henry RL. Cerebral abscess as a complication of cystic fibrosis. Pediatr Pulmonol 1994;17:390-2.

7. Kline MW. Brain abscess in a patient with cystic fibrosis. Pediatr Infect Dis 1985;4:72-3

8. Wiersbitzky SK, Bruns R, Ballke EH, et al. Multiple brain abscesses in a 25-year-old patient with cystic fibrosis, successfully treated with an anti-Pseudomonas plus anti-mycobacterial antibiotic regimen. Pediatr Pulmonol 1997;23:389-91

9. Sherman JM, Orenstein DM, Stern RC. Brain abscess and cystic fibrosis. J Pediatr 1980;96:952.

10. Rabkin CS, Blaser MJ. Brain abscess: A complication of cystic fibrosis in adults. Ann Neurol 1984;15:608-10. the lung (10). Our patient did not grow any positive cultures from the infected cerebral tissue, cerebrospinal fluid or blood cultures. The sputum culture was unchanged from the known colonizing microbes (Pseudomonas species and Klebsiella species).

\section{CONCLUSIONS}

A high index of suspicion for intracerebral abscess is required in patients with severe CF-related lung disease and headache. Our patient was afebrile and had no focal neurological findings, despite the presence of multiple intracerebral abscesses. Perhaps an earlier right-sided pneumonectomy may reduce or even eliminate the risk of brain abscess in the present patient. He is likely to have tolerated the resection because his right lung was not contributing to the measured lung function. We suggest that in cases such as ours, with a nonfunctioning lung and chronic or repeated infectious exacerbations, consideration should be given to pneumonectomy to reduce the risk of complications and improve the quality of life.

11. Gershan WM, Rusakow LS, Henrickson KJ, Splaingard ML. Brain abscess caused by Blastomyces dermatitidis in a child with cystic fibrosis. Chest 1994;106:601-3.

12. Liebovitch G, Maaravi Y, Shalev O. Multiple brain abscesses caused by Streptococcus bovis. J Infect 1991;23:195-6.

13. Mearns MB, Hodson CJ, Jackson AD, et al. Pulmonary resection in cystic fibrosis. Results in 23 cases, 1957-70. Arch Dis Child 1972:47:499-508.

14. Lucas J, Connett GJ, Lea R, Rolles CJ, Warner JO. Lung resection in cystic fibrosis patients with localised pulmonary disease. Arch Dis Child 1996;74:449-51.

15. Häusler M, Franke E, Wendt G, Kentrup H, Döhmen H, Kusenbach G. Pneumonectomy in cystic fibrosis. Pediatr Pulmonol 1999;28:376-9.

16. Piotrowski JA, Splittgerber FH, Donovan TJ, Ratjen F, Zerkowski HR. Single-lung transplantation in a patient with cystic fibrosis and an asymmetric thorax. Ann Thorac Surg 1997;64:1456-8.

17. Lucas JS, Connett GJ, Fairhurst J. Long term results of lung resection in cystic fibrosis patients with localized lung disease. Arch Dis Child 2002;86:66. 


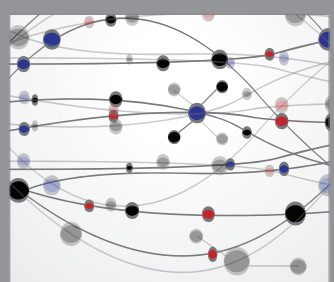

The Scientific World Journal
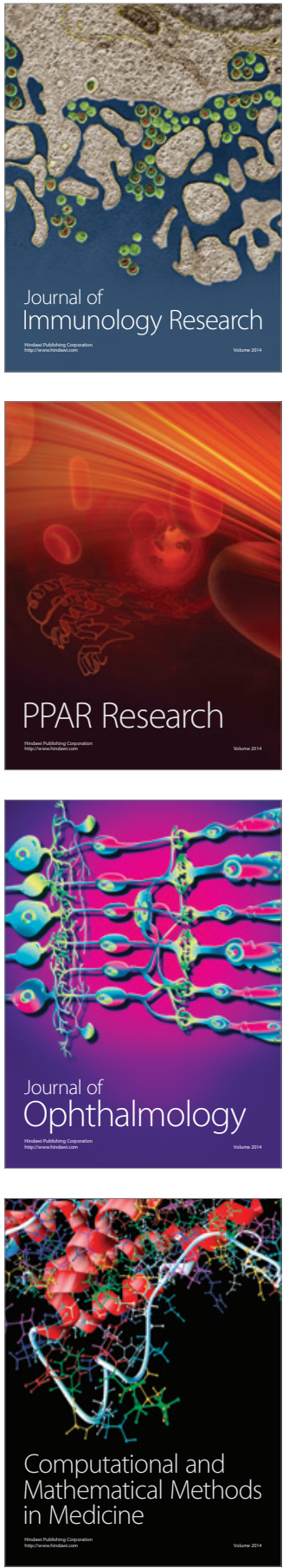

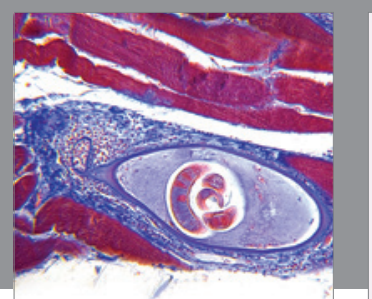

Gastroenterology Research and Practice

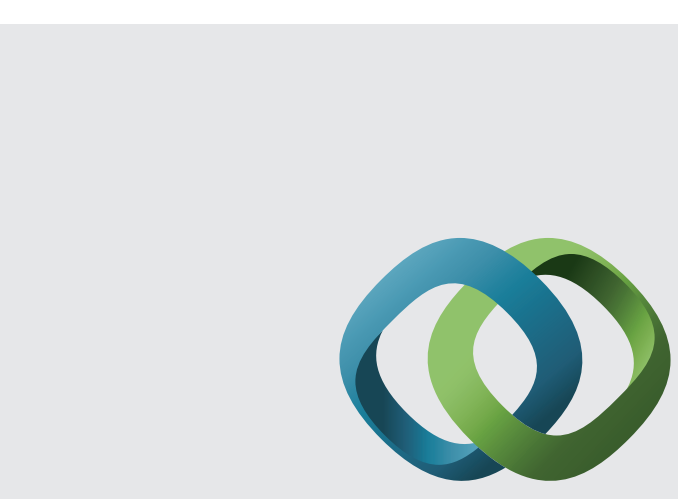

\section{Hindawi}

Submit your manuscripts at

http://www.hindawi.com
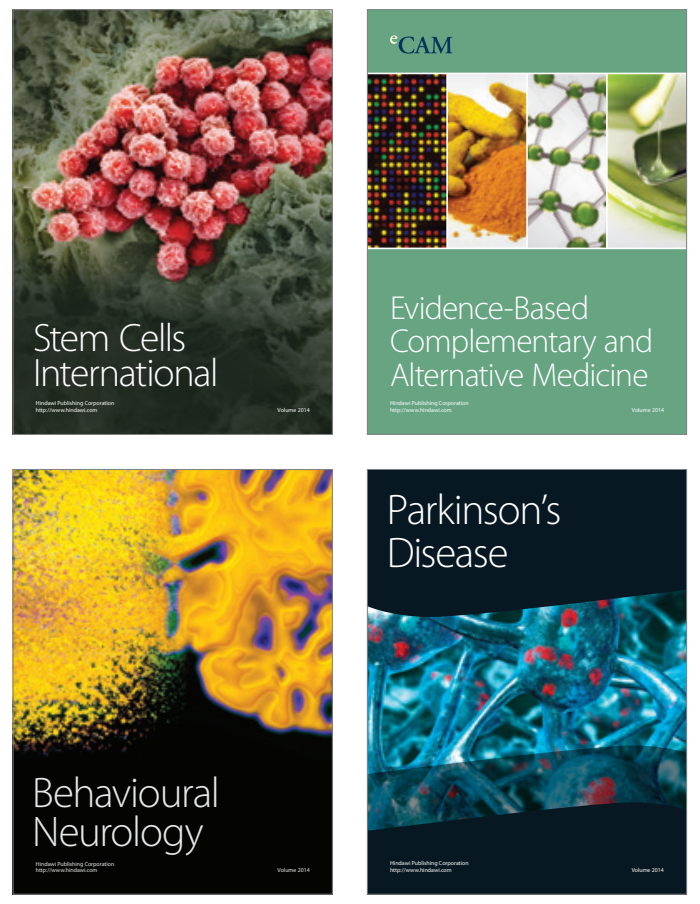
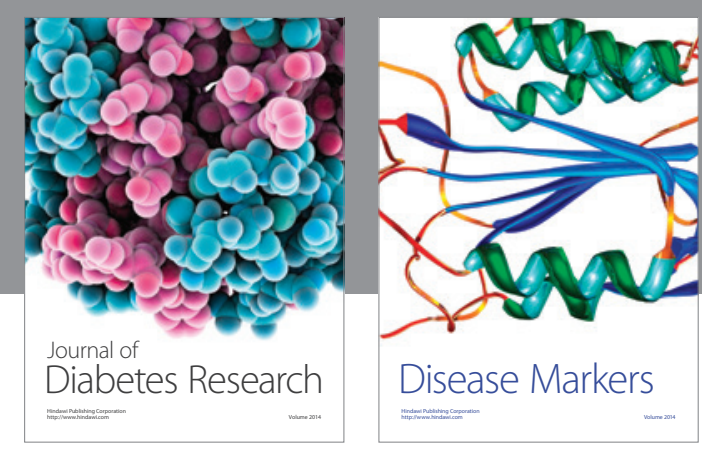

Disease Markers
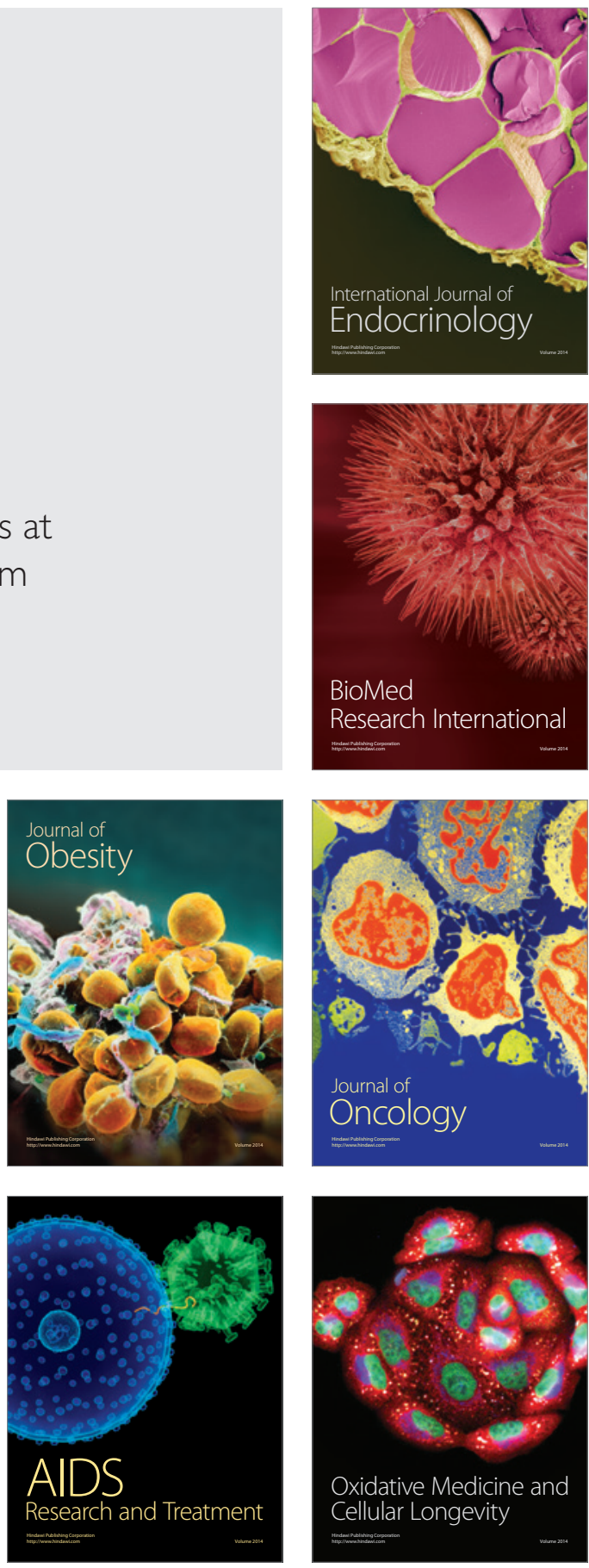